\title{
Graphite Nanoplatelet Modified Epoxy Resin for Carbon Fibre Reinforced Plastics with Enhanced Properties
}

\author{
Yan Li, ${ }^{1,2}$ Han Zhang, ${ }^{1,3}$ Zhaohui Huang, ${ }^{2}$ Emiliano Bilotti, ${ }^{1,3}$ and Ton Peijs ${ }^{1,3}$ \\ ${ }^{1}$ School of Engineering and Materials Science, Queen Mary University of London, London E1 4NS, UK \\ ${ }^{2}$ School of Materials Science and Technology, China University of Geosciences, Beijing, China \\ ${ }^{3}$ Nanoforce Technology Ltd., Joseph Priestley Building, Mile End Road, London E1 4NS, UK
}

Correspondence should be addressed to Emiliano Bilotti; e.bilotti@qmul.ac.uk and Ton Peijs; t.peijs@qmul.ac.uk

Received 5 December 2016; Accepted 16 January 2017; Published 28 February 2017

Academic Editor: Stefano Bellucci

Copyright (C) 2017 Yan Li et al. This is an open access article distributed under the Creative Commons Attribution License, which permits unrestricted use, distribution, and reproduction in any medium, provided the original work is properly cited.

\begin{abstract}
A simple approach to deliver graphene or graphite nanoplatelets (GNPs) into carbon fibre reinforced plastic (CFRPs) to enhance the multifunctional properties of carbon/epoxy laminates was demonstrated. GNPs improved the typically low interlaminar mechanical, thermal, and electrical properties of CFRPs after direct vacuum infusion of GNP doped resin obtained via in situ exfoliation by three-roll milling (TRM). Compared to high shear mixing or probe ultrasonication, TRM produces higher shear rates and stresses to exfoliate and finely disperse GNP particles within an epoxy matrix. This environmentally friendly and industrial scalable process does not require the use of solvents, additives, or chemical treatments. The flexural modulus and interlaminar shear strength (ILSS) of CFRPs was increased by $15 \%$ and by $18 \%$, respectively, with the addition of $5 \mathrm{wt} \%$ in situ exfoliated GNP in the doped epoxy resin. Out-of-plane electrical and thermal conductivity, at the same filler content, were, respectively, improved by nearly two orders of magnitude and $50 \%$.
\end{abstract}

\section{Introduction}

Carbon fibre reinforced plastics (CFRPs) are taking over traditional materials in many lightweight structural applications including aerospace, automobile, civil, and marine structures, because of their high specific stiffness and strength. Compared to the outstanding in-plane properties of composite laminates, the out-of-plane properties and delamination resistance of these laminated materials are less impressive. Because of this it is critical to improve interlaminar properties such as the interlaminar shear strength (ILSS) and interlaminar fracture toughness of CFRPs to fulfill wider applications. Many attempts have been made over the last few decades on improving their out-of-plane properties, such as the introduction of rubber or thermoplastic toughening agents in bulk resins [1-3] or interleaves [4-6], or through the addition of nanoparticles in bulk resins [7-9] or in interlaminar regions for localized toughening [10-13]. Among recent works, graphene and graphite nanoplatelet (GNP) are of particular interests for creating multiscale hierarchical composites with enhanced properties due to their excellent intrinsic mechanical, electrical, and thermal properties.

A wide range of techniques have been developed to introduce nanoparticles like GNP into composite laminates, including direct mixing of GNP into bulk resin [14], electrophoretic deposition (EPD) [15] and chemical vapour deposition (CVD) of GNPs onto reinforcing fabrics [16], the utilization of dissolvable interleafs as carriers to deliver GNPs [17], solvothermal methods [18], and spray coating [17]. Qin et al. [19] produced GNP coated carbon fibres by a simple dip coating procedure using a GNP solution and obtained a 19\% increment in ILSS with 3 wt.\% GNPs. Fan et al. [20] found that the thermal conductivity of GNP coated fibre laminates was $13 \%$ higher with the addition of 1 wt.\% GNP. Kostagiannakopoulou et al. [21] indicated that a $176 \%$ and $48 \%$ increase in thermal conductivity was achieved in nanomodified polymers and CFRPs, respectively, with the addition of $15 \mathrm{wt} . \%$ GNP into the epoxy matrix. Nevertheless, most of the GNP doped epoxy resins exhibit an increased viscosity which inhibits subsequent composite 
manufacturing processes like resin transfer moulding or vacuum infusion. Moreover, uneven GNP distribution and potential filtration of GNPs by the fibre preform can be another practical limiting factor [22].

In the present work, with the aim of fully exploiting the effects of GNPs in CFRPs, GNP doped resins were obtained by in situ exfoliation of natural graphite (NG) in epoxy to form hierarchical nanoengineered carbon fibre composites. The use of GNP doped resin via in situ exfoliation by threeroll milling (TRM) provided a feasible approach to deliver GNPs into CFRP in terms of simplicity and high yield. The resulting mechanical, electrical, and thermal properties of the obtained multiscale laminated composites were characterized and reported.

\section{Experimental}

2.1. Materials. Natural graphite (NG) was purchased from Alfa Aesar (Product No. 43319). The epoxy resin was an aerospace grade epoxy resin (MVR444), based on a resin (MVR444R) and hardener (MVR444H), supplied by Cytec Ltd. (UK). The mixing ratio of resin to hardener was $10: 5.8 \mathrm{w} / \mathrm{w}$. The composite system employed consisted of a high strength noncrimp T700 carbon fibre fabric (Toray Industries Inc., Product No. FCIM 557, ply construction $+45^{\circ} /-45^{\circ} /+45^{\circ}$, areal weight of $404 \mathrm{~g} / \mathrm{m}^{2}$, purchased from Formax, UK). T700 carbon fibre fabric/neat epoxy laminates were manufactured as baseline material. The mould release agent (Product No.: 700-NC) was purchased from Frekote, and an adhesive spray was purchased from $3 \mathrm{M}$ (Product No.: 10003901).

2.2. Fabrication of GNP Doped Resin. Three exfoliation and dispersion methods were initially utilised: (i) high shear mixing (HSM), (ii) probe sonication (PS), and (iii) three-roll milling (TRM). $4 \mathrm{~g} \mathrm{NG}$ was high shear mixed (IKA ${ }^{\circledR}$, Model T25DS2, Germany) in $40 \mathrm{~g}$ epoxy for $60 \mathrm{~min}$ at $2000 \mathrm{rpm}$. Probe sonication was also utilized to exfoliate NG in epoxy via sonication. Here $4 \mathrm{~g}$ NG was probe sonicated (Model GEX 750, $750 \mathrm{~W}, 20 \mathrm{kHz}$, Amplitude at 20\%, Power $1 \mathrm{sec}$ on $/ 1 \mathrm{sec}$ off) in $40 \mathrm{~g}$ epoxy for $60 \mathrm{~min}$ in an ice bath.

A three-roll mill (TRM, 80E EXAKT GmbH, Germany) was used to in situ exfoliate and disperse NG in neat epoxy resin without hardener to obtain a GNP doped resin in analogy to our previous paper [14]. In a typical experiment, the epoxy/NG mixture was passed 8 consecutive times through the TRM (referred to as 8 cycles), with the same rotational speed $(200 \mathrm{rpm})$ of the apron roll. The first two cycles were in gap mode (fixed roll-to-roll distance) while the following six cycles were in force mode (fixed applied force of $5.0 \mathrm{~N} / \mathrm{mm}$ ). Every cycle was performed at a fixed ratio of $1: 3: 9$ between $\mathrm{N}_{1}$ (feed roller) : $\mathrm{N}_{2}$ (central roller): $\mathrm{N}_{3}$ (apron roller). During the first cycle in gap mode, gaps of $\mathrm{N}_{1} / \mathrm{N}_{2}=120 \mu \mathrm{m}$ and $\mathrm{N}_{2} / \mathrm{N}_{3}$ $=40 \mu \mathrm{m}$ were used. For the second cycle, $\mathrm{N}_{1} / \mathrm{N}_{2}$ and $\mathrm{N}_{2} / \mathrm{N}_{3}$ were reduced to 60 and $20 \mu \mathrm{m}$, respectively. Temperature was maintained constant at $35^{\circ} \mathrm{C}$ for optimal exfoliation [14]. The resulting GNPs were characterized by thicknesses of 5 to $17 \mathrm{~nm}$ and aspect ratios ranging from 300 to 1000 . Vacuum assisted resin infusion (VARI) was used to manufacture GNP modified CFRP laminates using this GNP doped epoxy resin. Apart from the reference laminate based on neat epoxy resin, two GNP concentrations ( $2 \mathrm{wt} . \%$ and $5 \mathrm{wt} . \%$ ) were employed in this work. In order to obtain this filler loading in the final epoxy/hardener system, an initial GNP content of 3.1 wt.\% and 7.7 wt.\% was dispersed in neat epoxy resin by TRM. Hardener was added to the this epoxy/GNP mixture in a $58: 100$ ratio, resulting in a final filler loading of $2 \mathrm{wt} . \%$ and $5 \mathrm{wt} . \%$, respectively. This mixture was degassed in a vacuum chamber at $70^{\circ} \mathrm{C}$ for $60 \mathrm{~min}$ while mechanical stirring was applied throughout the process.

2.3. Fabrication of Composite Laminates. Standard vacuum assisted resin infusion (VARI) was used for all laminates. During the manufacturing of the CFRPs, a steel plate (cleaned first with acetone) was utilized as a base to create a VARI mould. This plate was treated three times with a Frekote mould release agent. Tacky tape was used to create the frame of the mould, with inlet and outlet tubes placed at both ends of the mould to facilitate resin flow. Fabrics of desired dimensions were placed inside the mould. Peel-ply was placed on top of the fabrics while a flow media was applied on top of the peel-ply to facilitate resin flow. The thickness of the produced laminates was between 3.5 and $3.6 \mathrm{~mm}$ and within testing standard requirements. T700 carbon fibre fabrics were infused with epoxy resin loaded with 2 wt.\% and $5 \mathrm{wt} . \%$ GNP using a VARI setup at a pressure of -1 bar. The following curing conditions were applied: (i) temperature was ramped from RT to $120^{\circ} \mathrm{C}\left(3^{\circ} \mathrm{C} \cdot \mathrm{min}^{-1}\right)$ followed by a $90 \mathrm{~min}$ isotherm, (ii) temperature was ramped from $120^{\circ} \mathrm{C}$ to $180^{\circ} \mathrm{C}$ at $\left(3^{\circ} \mathrm{C} \cdot \mathrm{min}^{-1}\right)$ followed by a $3 \mathrm{hrs}$ isotherm, and finally (iii) cooling down took place from $180^{\circ} \mathrm{C}$ to $\mathrm{RT}\left(3^{\circ} \mathrm{C} \cdot \mathrm{min}^{-1}\right)$. Specimens were cut into test specimen according to the testing standard using a diamond cutting wheel. No visible defects and dry spots were observed. The same procedures and parameters were applied for all neat resin reference specimens to highlight the effect of nanomodification.

\subsection{Characterization Techniques}

2.4.1. Morphological Analysis. Morphological studies were carried out using an optical microscope (OM, Olympus BX 60) and scanning electron microscopy (SEM, FEI Inspector-F) with an acceleration voltage of $20 \mathrm{kV}$. The $5 \mathrm{wt} . \%$ GNP/epoxy mixtures obtained via the various exfoliation and dispersion methods before cure were first observed by optical microscopy. The morphology of the cured GNP modified CFRP composites after gold coating was investigated by imaging the fracture surfaces using SEM.

2.4.2. ILSS Test. Interlaminar shear strength (ILSS) testing was carried out on an Instron (Instron 5566) using an ILSS test fixture in accordance with ASTM D 2344 [35]. As the loading cylinder exerts a downward force, the specimen is subjected to normal (bending) and transverse shear stresses. By using a short beam, it is assumed that the beam is short enough to minimize bending stresses resulting in 
an interlaminar shear failure mode and cracking along a horizontal plane between the laminates. The force applied at the time of failure was recorded and the stresses were determined using the equation

$$
S_{h}=\frac{0.75 P_{b}}{w h}
$$

where $S_{h}$ is the interlaminar shear strength $\left(\mathrm{N} / \mathrm{mm}^{2}\right), P_{b}$ is the breaking load $(\mathrm{N})$, and $w$ and $h$ are width and height of the specimen $(\mathrm{mm})$. A span to depth ratio of $4: 1$ was selected for the test. For each stacking sequence, five identical specimens were tested and average results reported. The width to height ratio of the specimens was 2 and the test rate was $1 \mathrm{~mm} / \mathrm{min}$. The average dimensions of the specimens was $40 \times 8 \times 4 \mathrm{~mm}^{3}$, respectively. The diameter of the loading roller was $6 \mathrm{~mm}$ and diameter of the support rollers was $3 \mathrm{~mm}$.

2.4.3. Flexural Test. Flexural test specimens were prepared according to the ASTM-D 7264 standard [36]. The samples were cut into beams of dimensions $4 \times 13 \times 150 \mathrm{~mm}^{3}$. The support span to depth ratio was $32: 1$ and a strain rate of $0.01 \mathrm{~mm} / \mathrm{min}$ was used. The flexural modulus of elasticity [37] was determined using the equation:

$$
E=\frac{L^{3} m}{4 w h^{3}},
$$

where $L(\mathrm{~mm})$ is the support span, $w(\mathrm{~mm})$ is the width of the beam, $h$ is the height of the beam, and $m$ is the slope of the secant of the force-deflection curve.

2.4.4. Electrical Test. The in-plane and out-of-plane electrical conductivities were obtained from two-point measurements using a picoammeter and a DC voltage source, on beam specimens with dimensions of $10 \times 30 \times 3 \mathrm{~mm}^{3}$. The surfaces of the samples were coated with silver paint to ensure good contact between the electrodes and samples. Measurements were performed on five specimens from each set of composites.

2.4.5. Thermal Test. Thermal diffusivity of GNP modified CFRP laminates and reference laminates were measured by a LFA MicroFlash ${ }^{\circledR}$ Laser Apparatus between 20 and $300^{\circ} \mathrm{C}$ using a circular sample with a diameter of $15 \mathrm{~mm}$ and a thickness of around $3.5 \mathrm{~mm}$.

\section{Results and Discussion}

3.1. Morphology of GNP and GNP/CFRP. Optical microscopy was used to compare the dispersion of the GNP/epoxy mixtures without hardener. Figure 1 shows the images from optical microscopy, demonstrating a significantly improved GNP exfoliation and dispersion for GNP modified resins obtained by three roll milling (TRM) (Figures 1(e) and 1(f)) [14], as compared to high shear mixing (HSM) (Figures 1(a) and $1(\mathrm{~b})$ ) and probe sonication (PS) (Figures 1(c) and 1(d)).

TRM produces higher shear rates and shear stresses enabling the effective exfoliation and dispersion of GNP particles within the epoxy matrix [14]. Another advantage of TRM, compared with high shear mixing and probe sonication, is that it can handle higher viscosities, typically up to $2 \times 10^{3} \mathrm{~Pa} \cdot \mathrm{s}$ [38]. However, very high GNP concentrations (>6 wt.\%) can still result in excessive viscosities which can inhibit the TRM process and, equally if not more importantly, the resin infusion process. Because TRM clearly produced better dispersions the remainder of this paper will only deal with doped epoxy resins that have been produced by in situ exfoliation/dispersion using TRM.

Figure 2 shows that the viscosity at $90^{\circ} \mathrm{C}$ of $5 \mathrm{wt} . \%$ GNP/epoxy without hardener obtained after 8 cycles of TRM exfoliation is as low as $0.3 \mathrm{~Pa} \cdot \mathrm{s}$, making it a good candidate for direct resin infusion. Indeed no particular difficulties were encountered in the vacuum infusion of $5 \mathrm{wt} . \%$ GNP doped epoxy systems, at $90^{\circ} \mathrm{C}$, for the manufacturing of composite panels of $20 \times 20 \mathrm{~cm}^{2}$.

To examine potential nanoparticle filtration effects of GNP modified epoxy/hardener systems during the resin infusion process, the cross sections of CFRP panels based on 5 wt.\% GNP modified epoxy along the infusion direction were studied. Figure 3 shows SEM images of cross sectional area of $5 \mathrm{wt}$ \% GNP/CFRP samples at inlet position (Figures 3(a) and 3(c)) and outlet position (Figures 3(b) and 3(d)) under different magnifications. GNP particles could equally be observed at the inlet as well as the outlet position with no clear evidence of a change in GNP concentration. This homogeneous dispersion of GNP within the panel will be further confirmed by electrical conductivity tests performed at different positions along the resin infusion direction (from inlet to outlet) which will be presented in Figure 4. It is interesting to note that GNP particles assumed a random (3D) orientation within the laminates with no evidence of any preferential planar orientation (see inset in Figures 3(a) and 3(b)).

3.2. Electrical Conductivity. Despite the fact that continuous carbon fibres are intrinsically conductive $\left(10^{3}-10^{6} \mathrm{~S} / \mathrm{m}\right)[39$, 40], it is expected that this property can be further improved with the addition of GNPs, particularly in the out-of-plane direction. The orientation of nanofillers within the polymer matrix, as well as its dispersion, does however play an important role [41, 42]. One could envisage either a preferential orientation in a specific (planar) direction, possibly along the resin flow path, or a more random orientation influenced by a "dynamic percolation" process before the epoxy resin is cured as indicated by the SEM pictures in Figure 3 [43, 44]. Electrical conductivity in both in-plane and out-ofplane direction is therefore measured for these nanomodified composite laminates (Figure 4).

It was found that the out-of-plane electrical conductivity of the CFRP laminates was increased by nearly two orders of magnitudes with the addition of $5 \mathrm{wt}$.\% GNP to the epoxy matrix (Figure 4(a)). On the other hand, in-plane electrical conductivity was only slightly affected by the addition of GNP. This suggests that the GNP assumes a more random orientation, bridging resin rich regions between carbon fibre fabrics, which conversely dominate the in-plane electrical conductivity. The measured out-of-plane and in-plane electrical conductivity increment indicate that the GNPs 


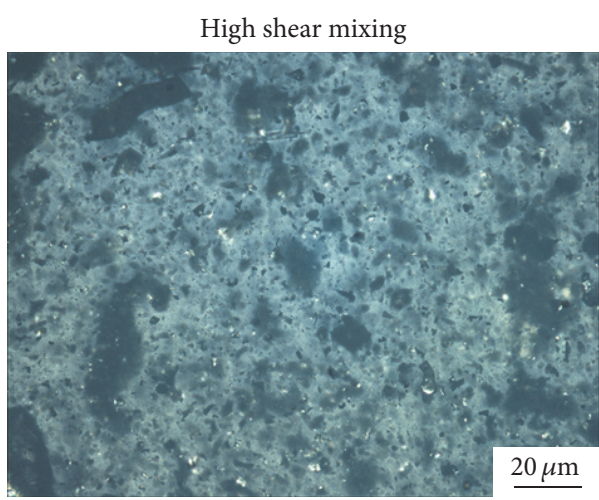

(a)

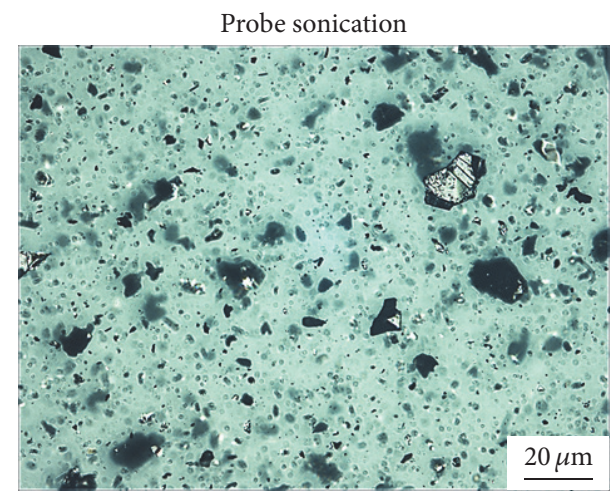

(c)

Three-roll mill

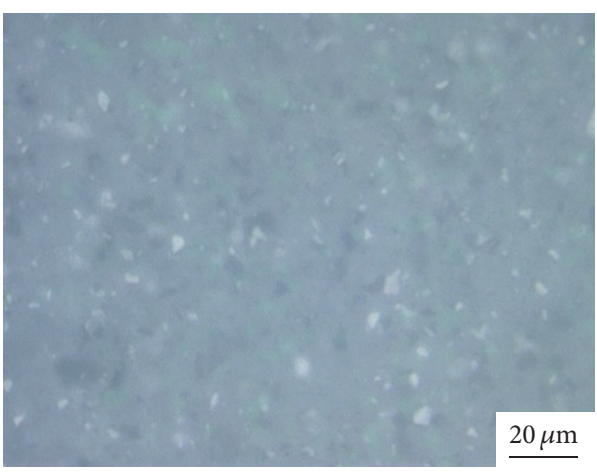

(e)

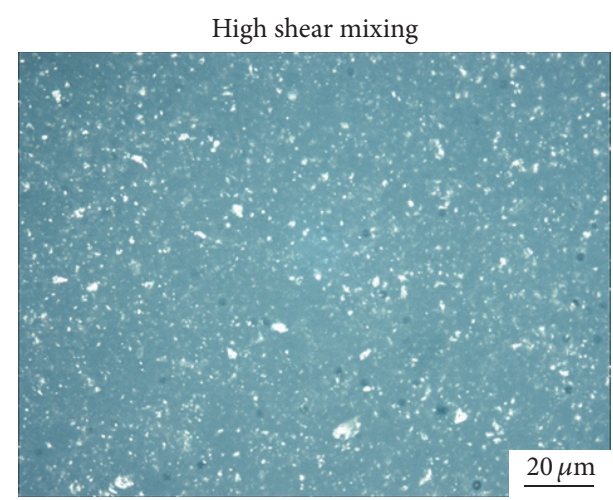

(b)

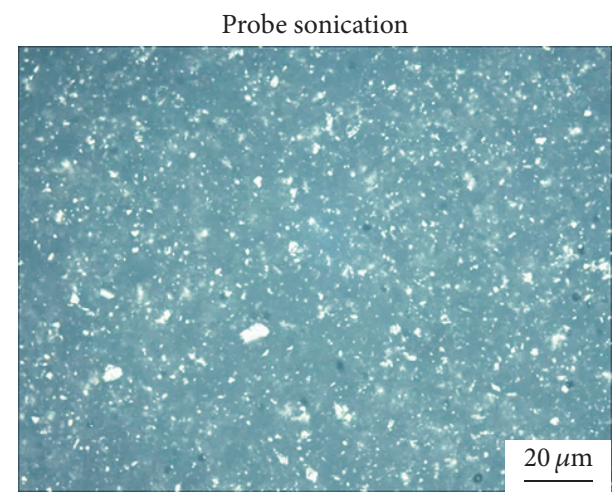

(d)

Three-roll mill

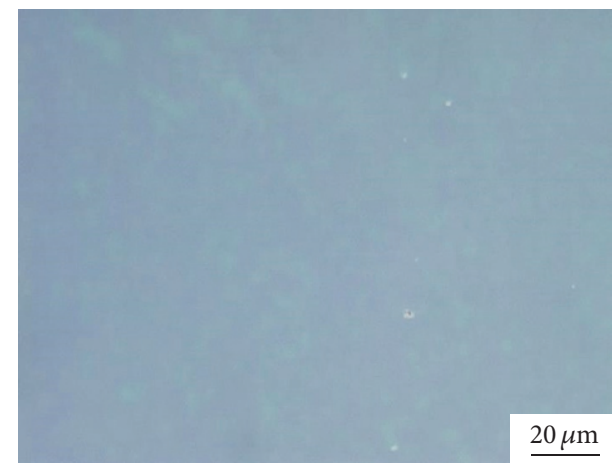

(f)

FIGURE 1: Optical microscopy images of 5 wt.\% NG/epoxy mixtures after various exfoliation/dispersion methods: (a) HSM 10 min @ 2000 rpm, (b) HSM 60 min @ 2000 rpm, (c) PS 10 min @ 20\% amplitude, (d) PS 60 min @ 20\% amplitude, (e) TRM @ 6 cycles, and (f) TRM @ 8 cycles.

provide conducting pathways along all directions in the $3 \mathrm{D}$ composite structure. Experimental results are also compared with representative data from literature in Table 1.

Qin et al. [19] reported that the incorporation of GNP in CFRP improved the out-of-plane electrical conductivity from $2.5 \mathrm{~S} / \mathrm{m}$ to $6.6 \mathrm{~S} / \mathrm{m}$ by creating a conductive path between carbon fibres. Kandare et al. [31] reported that the incorporation of GNP and silver nanoparticles (AgP)/nanowires (AgW) (e.g., CFRP/GNP/AgP and CFRP/GNP/AgW) at a combined loading of $1 \mathrm{vol} \% \%$ resulted in an out-of-plane electrical conductivity for CFRP composites of $0.26 \mathrm{~S} / \mathrm{m}$ and $0.33 \mathrm{~S} / \mathrm{m}$, respectively. The concomitant addition of GNP and AgP/AgW had a more profound effect $(\geq 70 \%$ enhancement) on the out-of-plane electrical conductivity of CFRP than the same loading fraction of GNP only $(0.16 \mathrm{~S} / \mathrm{m}$, $55 \%$ improvement @ 1vol.\% GNP alone). In the present work, the average increment in out-of-plane and in-plane conductivities for $5 \mathrm{wt}$ \% GNP modified CFRP was nearly two orders of magnitude.

The conductivity measurements offer also a valuable tool to investigate any potential filtration effects of GNP during resin infusion, by measuring the local electrical conductivity 


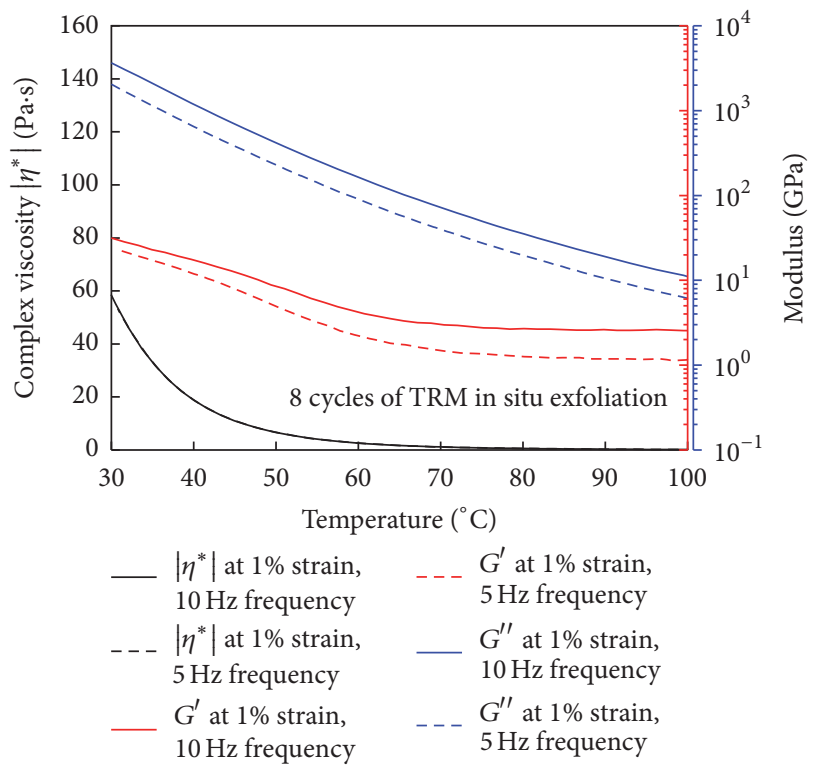

FIGURE 2: The complex viscosity of $5 \mathrm{wt}$ \% GNP/epoxy in situ exfoliated by TRM.

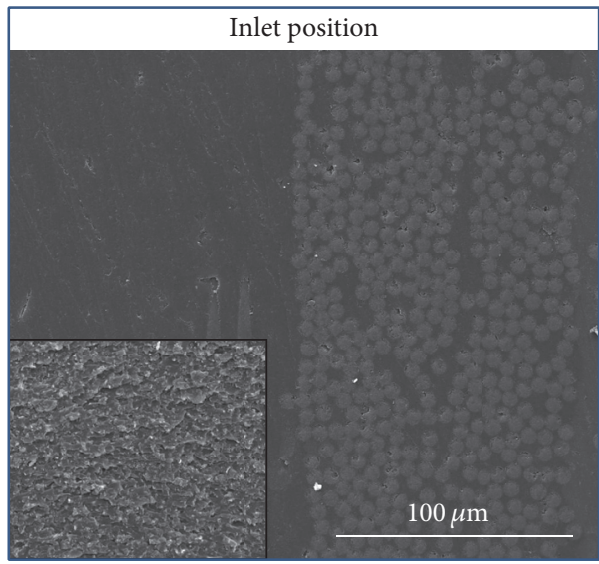

(a)

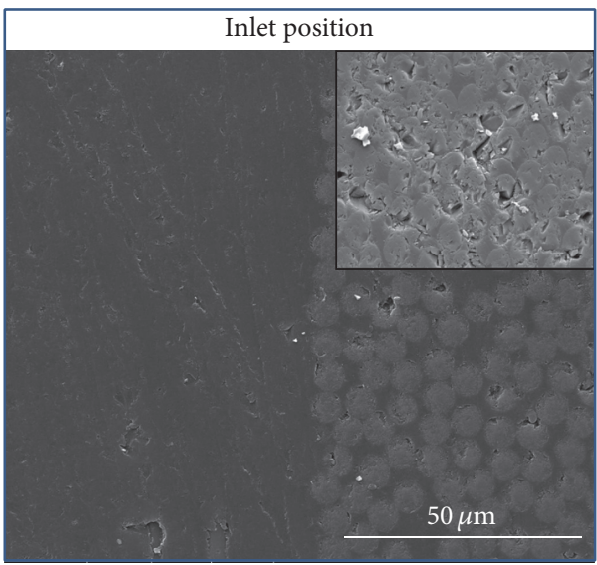

(c)

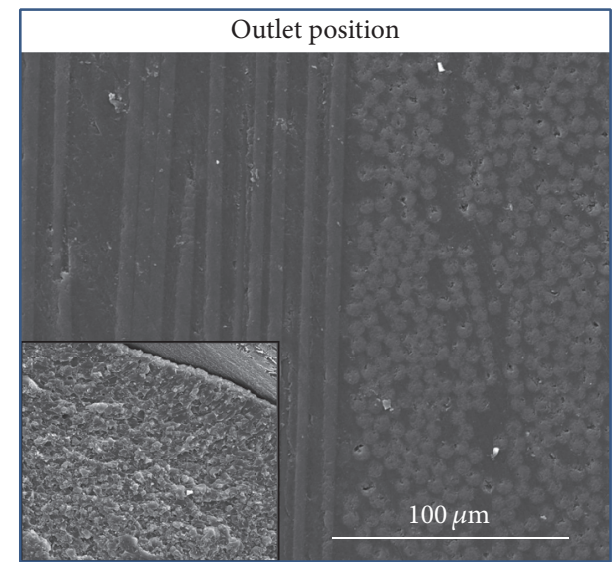

(b)

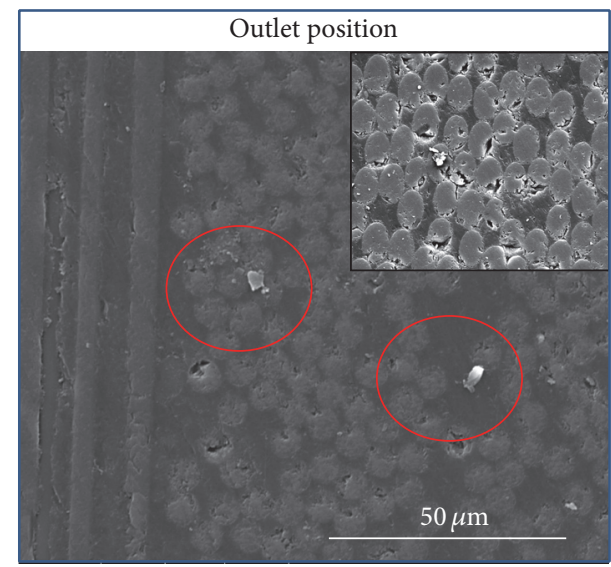

(d)

FIGURE 3: SEM images of cross sections of $5 \mathrm{wt}$ \% GNP/CFRP samples at inlet (a, c) and outlet (b, d) positions. 


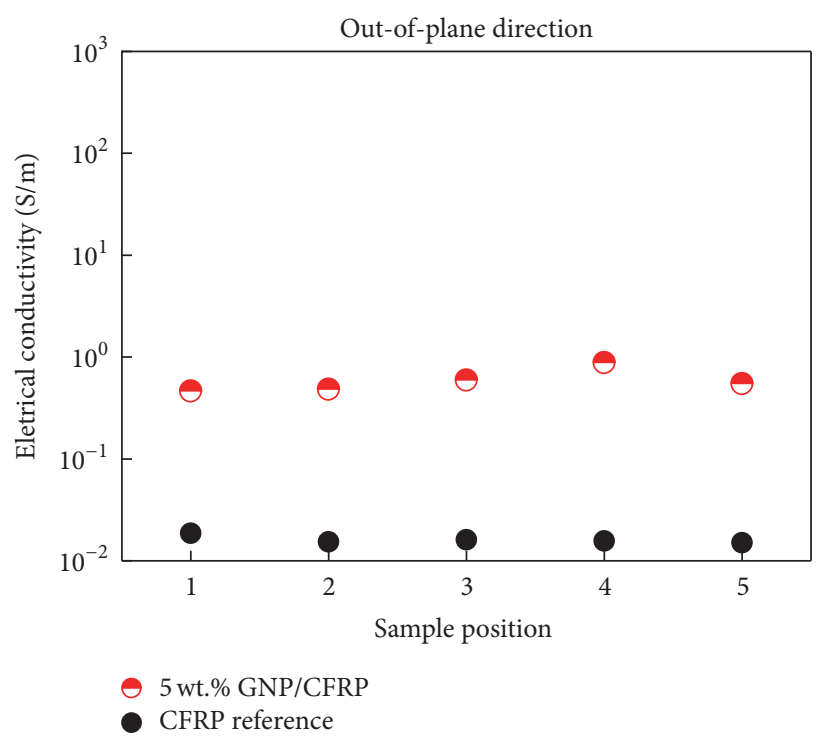

(a)

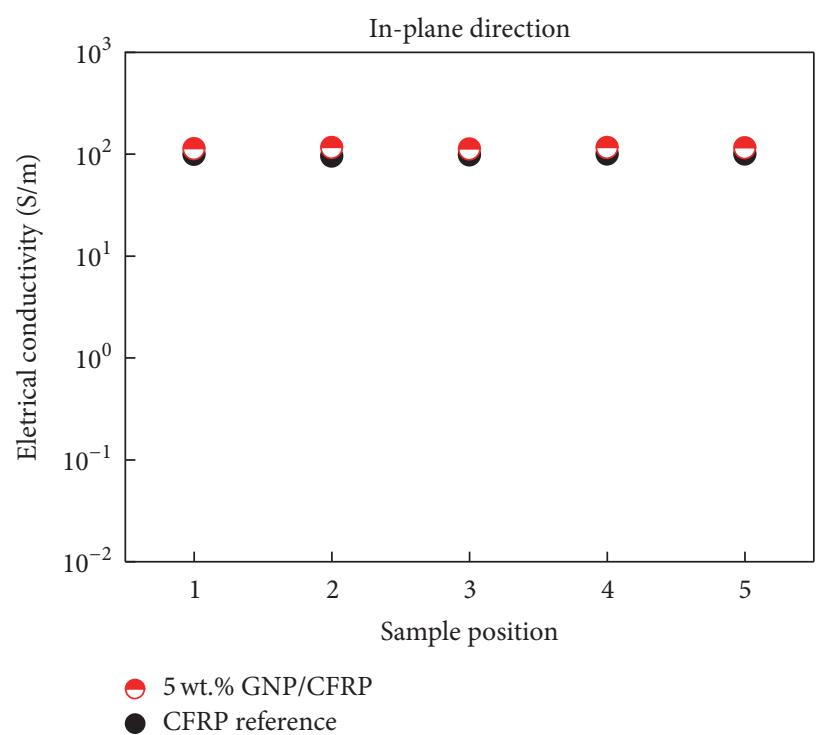

(b)

Figure 4: (a) Out-of-plane and (b) in-plane electrical conductivity of 5 wt.\% GNP/CFRP (samples 1-5 measured at five positions along the panel injection length from inlet (1) to outlet (5)).

TABLE 1: Electrical conductivity of various nanofiller modified composites.

\begin{tabular}{|c|c|c|c|c|c|}
\hline Composite & Matrix/fibre & Filler & Content & $\sigma(\mathrm{S} / \mathrm{m})$ & Refs. \\
\hline CFRP/AgNP & Epoxy/carbon & AgNP & 0.05 vol. $\%$ & $\sigma_{\|}=0.25$ & [31] \\
\hline CFRP/GNP & Epoxy/carbon & GNP & 1 vol.\% & 0.17 & - \\
\hline GFRP/GNP & Epoxy/glass & $\mathrm{NH}_{2}-\mathrm{GNP}$ & 2 wt.\% & $10^{-8}$ & {$[32]$} \\
\hline GFRP/GNP & Epoxy/glass & $\mathrm{NH}_{2}$-GNP & 8 wt.\% & $10^{-5}$ & - \\
\hline GFRP/GNP & Epoxy/glass & $\mathrm{NH}_{2}-\mathrm{GNP}$ & 12 wt. $\%$ & $10^{-4}$ & - \\
\hline GFRP/CB & Epoxy/glass & $\mathrm{CB}$ & 0.3 wt. $\%$ & $10^{-4}$ & {$[33]$} \\
\hline GFRP/CB & Epoxy/glass & $\mathrm{CB}$ & 2 wt. $\%$ & $7.69 \times 10^{-2}$ & {$[34]$} \\
\hline CFRP/GNP & Epoxy/carbon & GNP & $5 w t . \%$ & 0.60 & This study \\
\hline
\end{tabular}

along the infusion path. Specimens at various locations along the resin flow path were examined. Figure 4 shows the electrical conductivity of manufactured lab-scale laminates $(20 \times$ $20 \mathrm{~cm}^{2}$ ) at different positions along the resin flow direction, with each sample number measured at $3 \mathrm{~cm}$ intervals. In all cases, a fairly constant conductivity along the resin flow path was observed, suggesting no obvious filtration effects at current panel dimensions, confirming the SEM observation on Figure 3. It should be noted, however, that our panels are rather small and filtration of GNP in larger panels cannot be excluded.

3.3. Mechanical Properties. The in-plane mechanical properties of continuous carbon fibre reinforced composites are already excellent and they are not expected to be significantly affected by the introduction of nanofillers. However, matrixor interface-dominated properties like interlaminar shear strength (ILSS) are more likely to be affected. In this work, the short beam shear method was used to investigate the influence of the GNPs on interlaminar properties. In the case of good interfacial bonding between nanofiller and matrix and controlled nanoparticle dispersion, the interlaminar properties of CFRP could be significantly improved.

The introduction of $5 \mathrm{wt} . \%$ GNP into the epoxy matrix increased the ILSS and flexural modulus of the CFRP by $18 \%$ and $13 \%$, respectively (Figure $5(\mathrm{a})$ ). It is known that composites with low ILSS are prone to delamination and have poor resistance to environmental degradation, which is detrimental to many applications. GNPs could reinforce and toughen the epoxy matrix fairly efficiently because of their homogeneous 3D filler orientation and distribution, which ensures some interaction with a propagating crack. By this the GNPs also act as a bridge, increasing the mechanical interaction between fibres and matrix within the interphase region, reducing the interlaminar stress concentrations at a given load [19, 45, 46]. Previous studies showed that the addition of graphene oxide (GO) can achieve an enhancement of the ILSS of CFRP via different processing routes: using a wet process for the impregnation of carbon fibres with GO modified epoxy [47]; the cografting of GO and POSS increasing of fibre surface energy and wettability [23]; electrophoretic deposition (EPD) of GO on carbon fibre [48]; 


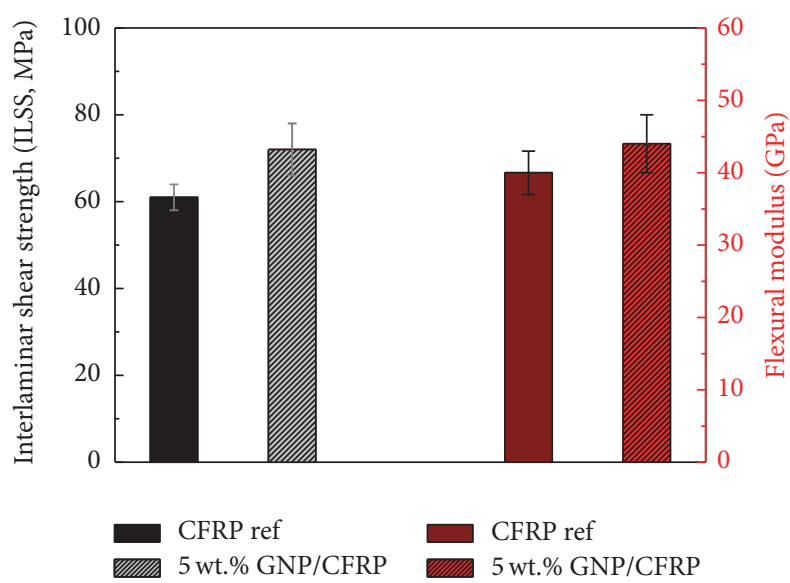

(a)

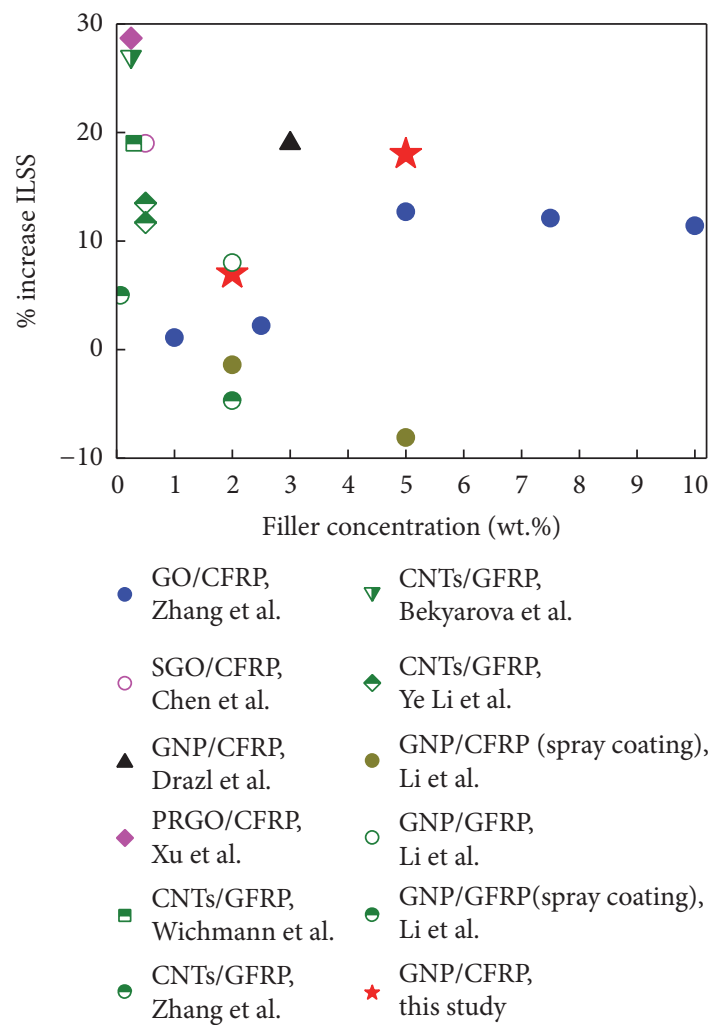

(b)

FIGURE 5: (a) ILSS and flexural modulus of CFRP reference panel and 5 wt.\% GNP modified CFRP panel; (b) relative percentage increase in ILSS of CFRP/GFRP composites modified by different nanofillers from literature together with data from this study (Red star) $[17,19,23-30]$.

and direct introduction of GO in the fibre sizing of individual carbon fibres [26].

GO could also lead to a significant increase of fibre surface energy and wettability, enhancing mechanical properties by increasing the fibre surface area. The increased surface roughness can also significantly enhance the interfacial interaction by improving the fibre surface wetting and mechanical interlocking between fibre and matrix.
CNTs have also been reported to increase the ILSS of laminated composites. CNTs have been introduced via different routes, including doped resins [9], spray coating of CNT suspensions on fibre fabrics [27]; electrophoresis deposition (EPD) of CNTs on carbon fabrics [28]; growth of MWCNTs on the surface of fibre fabrics [29]; or the addition of plasma-functionalized MWCNTs [30]. Compared to these routes, direct vacuum infusion of GNP doped resin is the simplest method to deliver GNPs into composite laminates for enhanced multifunctional properties. The resulting nanoengineered composites show potentially improved mechanical performance for applications in aerospace, sports, and automotive industries. Figure 5(b) gives an overview of the relative increase in ILSS of carbon and glass fibre reinforced composites with the addition of different carbon nanofillers as reported in literature together with data from this study (red star). Clearly, the improvement in ILSS as obtained for the $5 \mathrm{wt} . \%$ GNP sample is among the highest reported for these types of nanomodified composite systems.

3.4. Thermal Conductivity. The thermal conductivity of 5 wt.\% GNP doped resin systems as obtained by TRM in situ exfoliation is $0.65 \mathrm{~W} \cdot \mathrm{m}^{-1} \cdot \mathrm{K}^{-1}$ at room temperature [30]. Due to its high surface area and flat shape, GNP has a higher effective contact surface area than CNT, thus when embedded into polymer matrices GNPs permit a much closer areal contact between adjacent platelets. Hence, the thin epoxy layer between the nanofillers, which is responsible for the phonon scattering due to the conductivity mismatch between thermally conductive nanofillers and insulating epoxy matrix, is reduced. Besides, GNPs provide 2D pathways that contribute more effectively to phonon transport than $1 \mathrm{D}$ pathways as provided by CNTs [49]. The addition of flat-shaped GNPs into epoxy resins has a much smaller effect on the resin viscosity in comparison to the incorporation of entangled CNT networks. This allows for a much wider processing window and the incorporation of relatively high filler contents which is necessary in order to achieve a high thermal conductivity. At the same time the resulting agglomerates are limited in the case of GNPs, CNTs cannot reach such high filler contents because they show severe entanglements due to their 1D flexible fibrous structure even at relatively low filler contents (>1 wt.\%) [21].

Improvements in thermal conductivity $(\lambda)$ were found in GNP modified CFRPs. The out-of-plane thermal conductivity of CFRP was improved by $8 \%$ and $50 \%$, respectively, with the addition of 2 wt.\% and 5 wt.\% GNP (Figure 6(a)). Phenomenological analytical models proposed by Hashin and Clayton [21] were used to predict the out-of-plane thermal conductivity of GNP nanomodified CFRPs (Figure 6(b)). It is evident that both models fit well the experimental data at $2 \mathrm{wt} . \%$ and $5 \mathrm{wt} . \%$ GNP content into the epoxy matrix, in agreement with literature [21]. However, both models show larger deviations at higher filler loadings (>5 wt.\%) [17] in the case of GNP doped resin due to viscosity or agglomeration problems. Both Hashin's model and Clayton's model are based on the thermal conductivity of the individual constituents 


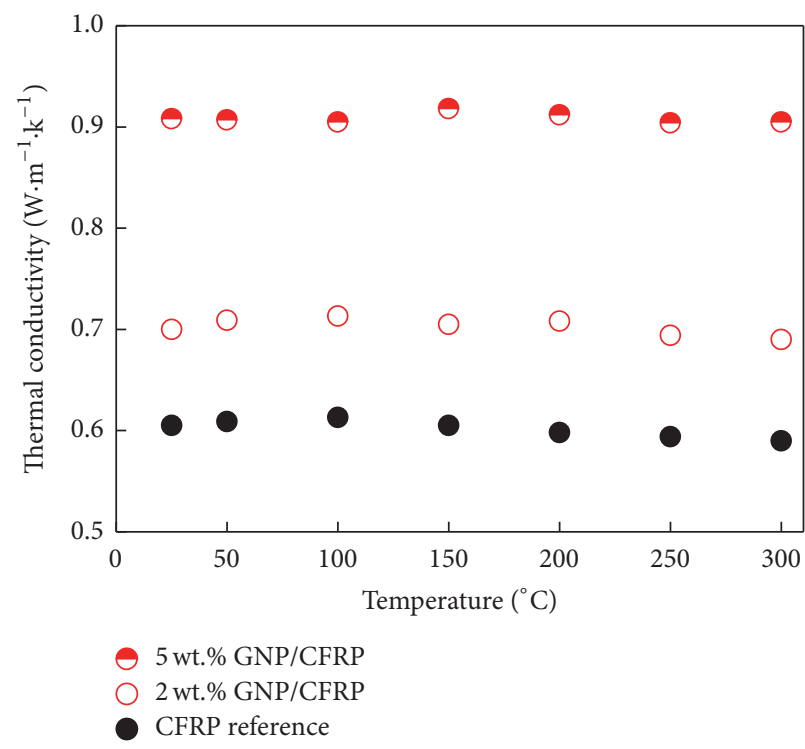

(a)

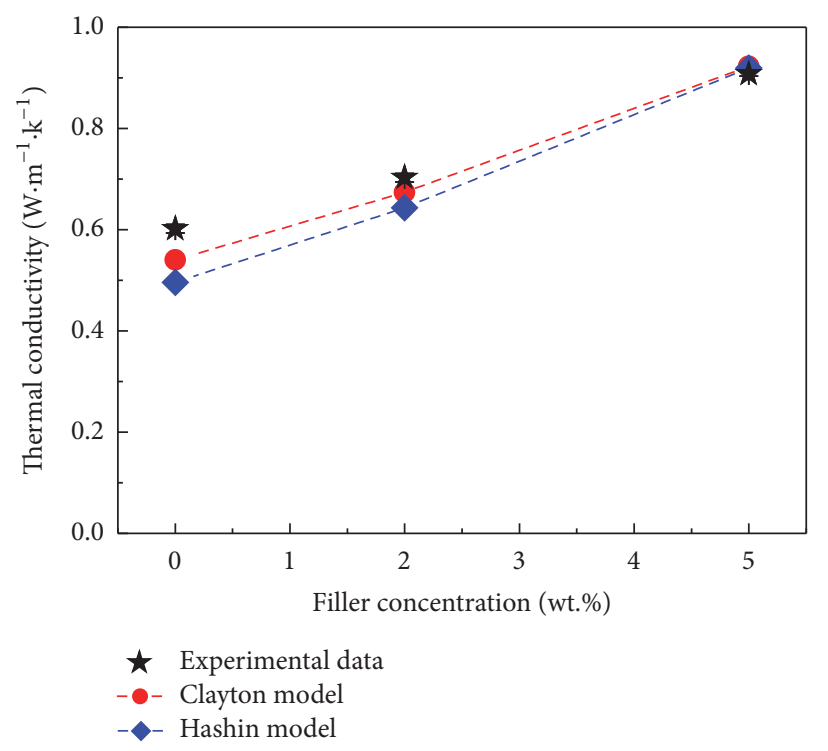

(b)

FIGURE 6: (a) The thermal conductivity of CFRP reference panel, 2 wt.\% and 5 wt.\% GNP modified CFRP panel under different temperatures; (b) comparative plots of Clayton and Hashin models together with experimental data of GNP modified CFRP.

and their volume fractions, and based on the following assumptions: (a) the heat energy transfer between phases takes place through conduction; (b) the discontinuous phase (filler) is homogeneously dispersed in the continuous phase (matrix); (c) the nanomodified polymers can be considered macroscopically homogeneous and thermally isotropic; (d) the composites can be considered macroscopically transversely thermally isotropic.

Hashin Model

$$
\lambda=\lambda_{m}\left[\frac{\lambda_{m} v_{m}+\lambda_{f}\left(1+v_{f}\right)}{\lambda_{m}\left(1+v_{f}\right)+\lambda_{f} v_{m}}\right]
$$

\section{Clayton Model}

$$
\begin{aligned}
\lambda= & \frac{\lambda_{m}}{4}\left[\sqrt{\left(1-v_{f}\right)_{2}\left(\frac{\lambda_{f}}{\lambda_{m}}-1\right)^{2}+\frac{4 \lambda_{f}}{\lambda_{m}}}\right. \\
& \left.-\left(1-v_{f}\right)\left(\frac{\lambda_{f}}{\lambda_{m}}-1\right)^{2}\right],
\end{aligned}
$$

where, $\lambda$ is the equivalent thermal conductivity (for CFRP only in out-of-plane direction); $\lambda_{m}$ and $\lambda_{f}$ are the thermal conductivities of matrix and fibre; $v_{m}$ and $v_{f}$ are the volume fraction of matrix and fibre. The thermal conductivity of carbon fibre (T700) and epoxy resin MVR 444 used are $10.2 \mathrm{~W} \cdot \mathrm{m}^{-1} \cdot \mathrm{K}^{-1}[50]$ and $0.14 \mathrm{~W} \cdot \mathrm{m}^{-1} \cdot \mathrm{K}^{-1}$, respectively.

Fan et al. [20] found that the thermal conductivity of the GNP coated carbon fibre/epoxy composites was 13\% higher owing to the addition of $1 \mathrm{wt} . \%$ GNP. Park et al. [51] and
Wan et al. [52] pointed out the enhancement of thermal conductivities of composites with increasing temperature. However, in the current composites we observed no significant increase in thermal conductivity with increased temperature (Figure 6(a)). The out-of-plane thermal conductivity of the CFRP laminates was around $0.6 \mathrm{~W} \cdot \mathrm{m}^{-1} \cdot \mathrm{K}^{-1}$, which is in accordance with reported values in literature (using the same carbon T700 fibre, but a different resin, $0.69 \mathrm{~W} \cdot \mathrm{m}^{-1} \cdot \mathrm{K}^{-1}$ ) [50].

Similar to the previous discussion concerning electrical conductivity, Kandare et al. [31] found that the incorporation of GNP together with silver nanoparticles/nanowires at a combined hybrid nanofiller loading of 1 vol.\% resulted in an approximate $40 \%$ increase in out-of-plane thermal conductivity but only a $9 \%$ improvement at 1 vol. $\%$ GNP.

\section{Conclusions}

Well-dispersed GNP doped epoxy resins were produced by three-roll milling (TRM) and used to create nanoengineered CFRPs with enhanced (out-of-plane) properties. In situ exfoliation/dispersion of GNPs in epoxy resin by TRM followed by direct vacuum infusion of this doped resin system is a feasible route to create nanomodified CFRPs in terms of simplicity as no additional organic solvents or intermediate steps (e.g., filtration, removal of dispersing medium, purification, drying of powder, redispersion into the final matrix, etc.) are needed.

The flexural modulus and ILSS of CFRP panels based on 5 wt. $\%$ GNP modified epoxy was increased by $15 \%$ and $18 \%$, respectively. No filtration effects were noticed for lab scale infused panels although this may remain a potential issue in the case of larger panels and higher GNP loadings. The out-of-plane thermal conductivity of $5 \mathrm{wt} . \%$ GNP modified 
CFRP was improved by $50 \%$. The viscosity of the GNP doped resin did not negatively affect the VARI process at an infusion temperature of $90^{\circ} \mathrm{C}$. Furthermore, there was no visible degradation of the surface finish and hence this processing method may be of interest for future application of GNPs in structural composites.

\section{Competing Interests}

The authors declare that there is no conflict of interests regarding the publication of this paper.

\section{Acknowledgments}

This research has received funding from the NanoSynth Project which is funded by Innovate UK through the Technology Inspired Innovation NANO Competition under Project no. 101257. Yan Li would like to acknowledge financial support through the China Scholarship Council (CSC).

\section{References}

[1] R. Bagheri, B. T. Marouf, and R. A. Pearson, "Rubber-toughened epoxies: a critical review, Polymer Reviews, vol. 49, no. 3, pp. 201-225, 2009.

[2] J. H. Hodgkin, G. P. Simon, and R. J. Varley, "Thermoplastic toughening of epoxy resins: a critical review," Polymers for Advanced Technologies, vol. 9, no. 1, pp. 3-10, 1998.

[3] R. W. Venderbosch, T. Peijs, H. E. H. Meijer, and P. L. Lemstra, "Fibre-reinforced composites with tailored interphases using PPE/epoxy blends as a matrix system," Composites Part A: Applied Science and Manufacturing, vol. 27, no. 9, pp. 895-905, 1996.

[4] N. Sela and O. Ishai, "Interlaminar fracture toughness and toughening of laminated composite materials: a review," Composites, vol. 20, no. 5, pp. 423-435, 1989.

[5] D. W. Y. Wong, L. Lin, P. T. McGrail, T. Peijs, and P. J. Hogg, "Improved fracture toughness of carbon fibre/epoxy composite laminates using dissolvable thermoplastic fibres," Composites Part A: Applied Science and Manufacturing, vol. 41, no. 6, pp. 759-767, 2010.

[6] H. Zhang, A. Bharti, Z. Li, S. Du, E. Bilotti, and T. Peijs, "Localized toughening of carbon/epoxy laminates using dissolvable thermoplastic interleaves and electrospun fibres," Composites Part A: Applied Science and Manufacturing, vol. 79, pp. 116-126, 2015.

[7] B. B. Johnsen, A. J. Kinloch, R. D. Mohammed, A. C. Taylor, and S. Sprenger, "Toughening mechanisms of nanoparticlemodified epoxy polymers," Polymer, vol. 48, no. 2, pp. 530-541, 2007.

[8] H. Qian, E. S. Greenhalgh, M. S. P. Shaffer, and A. Bismarck, "Carbon nanotube-based hierarchical composites: a review," Journal of Materials Chemistry, vol. 20, no. 23, pp. 4751-4762, 2010.

[9] F. Inam, D. W. Y. Wong, M. Kuwata, and T. Peijs, "Multiscale hybrid micro-nanocomposites based on carbon nanotubes and carbon fibers," Journal of Nanomaterials, vol. 2010, Article ID 453420, 12 pages, 2010.

[10] S. S. Wicks, R. G. de Villoria, and B. L. Wardle, "Interlaminar and intralaminar reinforcement of composite laminates with aligned carbon nanotubes," Composites Science and Technology, vol. 70, no. 1, pp. 20-28, 2010.

[11] H. Zhang, Y. Liu, M. Kuwata, E. Bilotti, and T. Peijs, "Improved fracture toughness and integrated damage sensing capability by spray coated CNTs on carbon fibre prepreg," Composites Part A: Applied Science and Manufacturing, vol. 70, pp. 102-110, 2015.

[12] A. Haesch, T. Clarkson, J. Ivens, S. V. Lomov, I. Verpoest, and L. Gorbatikh, "Localization of carbon nanotubes in resin rich zones of a woven composite linked to the dispersion state," Nanocomposites, vol. 1, no. 4, pp. 204-213, 2015.

[13] H. Zhang, E. Bilotti, and T. Peijs, "The use of carbon nanotubes for damage sensing and structural health monitoring in laminated composites: a review," Nanocomposites, vol. 1, no. 4, pp. 167-184, 2015.

[14] Y. Li, H. Zhang, M. Crespo et al., "In situ exfoliation of graphene in epoxy resins: a facile strategy to efficient and large scale graphene nanocomposites," ACS Applied Materials \& Interfaces, vol. 8, no. 36, pp. 24112-24122, 2016.

[15] J. K. Park, I.-H. Do, P. Askeland, and L. T. Drzal, "Electrodeposition of exfoliated graphite nanoplatelets onto carbon fibers and properties of their epoxy composites," Composites Science and Technology, vol. 68, no. 7-8, pp. 1734-1741, 2008.

[16] X. Li, P. Sun, L. Fan et al., "Multifunctional graphene woven fabrics," Scientific Reports, vol. 2, article 395, 2012.

[17] Y. Li, H. Zhang, T. Peijs, and E. Bilotti, "Graphene delivery systems for hierarchical fiber reinforced composites," MRS Advances, vol. 1, no. 19, pp. 1339-1344, 2016.

[18] J. Qian, J. Wu, X. Liu, Q. Zhuang, and Z. Han, "Improvement of interfacial shear strengths of polybenzobisoxazole fiber/epoxy resin composite by $\mathrm{n}-\mathrm{TiO}_{2}$ coating," Journal of Applied Polymer Science, vol. 127, no. 4, pp. 2990-2995, 2013.

[19] W. Qin, F. Vautard, L. T. Drzal, and J. Yu, "Mechanical and electrical properties of carbon fiber composites with incorporation of graphene nanoplatelets at the fiber-matrix interphase," Composites Part B: Engineering, vol. 69, pp. 335-341, 2015.

[20] W. Fan, J.-L. Li, and Y.-Y. Zheng, "Improved thermo-oxidative stability of three-dimensional and four-directional braided carbon fiber/epoxy hierarchical composites using graphenereinforced gradient interface layer," Polymer Testing, vol. 44, article 4426, pp. 177-185, 2015.

[21] C. Kostagiannakopoulou, E. Fiamegkou, G. Sotiriadis, and V. Kostopoulos, "Thermal conductivity of carbon nanoreinforced epoxy composites," Journal of Nanomaterials, vol. 2016, Article ID 1847325, 12 pages, 2016.

[22] H. Zhang, Y. Liu, S. Huo et al., "Filtration effects of graphene nanoplatelets in resin infusion processes: problems and possible solutions," Composites Science and Technology, vol. 139, pp. 138145, 2017.

[23] R. L. Zhang, B. Gao, W. T. Du et al., "Enhanced mechanical properties of multiscale carbon fiber/epoxy composites by fiber surface treatment with graphene oxide/polyhedral oligomeric silsesquioxane," Composites Part A: Applied Science and Manufacturing, vol. 84, pp. 455-463, 2016.

[24] P. Xu, P. Cong, Z. Gao et al., "High performance graphene oxidemodified polybenzoxazine resin," Polymer Composites, vol. 37, no. 5, pp. 1507-1514, 2016.

[25] L. Chen, H. Jin, Z. Xu et al., "A design of gradient interphase reinforced by silanized graphene oxide and its effect on carbon fiber/epoxy interface," Materials Chemistry and Physics, vol. 145, no. 1-2, pp. 186-196, 2014. 
[26] X. Zhang, X. Fan, C. Yan et al., "Interfacial microstructure and properties of carbon fiber composites modified with graphene oxide," ACS Applied Materials and Interfaces, vol. 4, no. 3, pp. 1543-1552, 2012.

[27] H. Zhang, M. Kuwata, E. Bilotti, and T. Peijs, "Integrated damage sensing in fibre-reinforced composites with extremely low carbon nanotube loadings," Journal of Nanomaterials, vol. 2015, Article ID 785834, 7 pages, 2015.

[28] E. Bekyarova, E. T. Thostenson, A. Yu et al., "Multiscale carbon nanotube-carbon fiber reinforcement for advanced epoxy composites," Langmuir, vol. 23, no. 7, pp. 3970-3974, 2007.

[29] V. P. Veedu, A. Cao, X. Li et al., "Multifunctional composites using reinforced laminae with carbon-nanotube forests," Nature Materials, vol. 5, no. 6, pp. 457-462, 2006.

[30] J. Li, Z. Wu, C. Huang, Y. Tu, and L. Li, "Simultaneous enhancements in the mechanical, thermal, and electrical performances of glass-fiber-reinforced cyanate ester/epoxy composites with plasma-functionalized carbon nanotubes at different temperatures," Journal of Applied Polymer Science, vol. 132, no. 6, Article ID 41418, 2015.

[31] E. Kandare, A. A. Khatibi, S. Yoo et al., "Improving the through-thickness thermal and electrical conductivity of carbon fibre/epoxy laminates by exploiting synergy between graphene and silver nano-inclusions," Composites Part A: Applied Science and Manufacturing, vol. 69, pp. 72-82, 2015.

[32] R. Moriche, M. Sánchez, A. Jiménez-Suárez, S. G. Prolongo, and A. Ureña, "Electrically conductive functionalized-GNP/epoxy based composites: from nanocomposite to multiscale glass fibre composite material," Composites Part B: Engineering, vol. 98, pp. 49-55, 2016.

[33] C. Li and T.-W. Chou, "Modeling of damage sensing in fiber composites using carbon nanotube networks," Composites Science and Technology, vol. 68, no. 15-16, pp. 3373-3379, 2008.

[34] D. Zhang, L. Ye, D. Wang, Y. Tang, S. Mustapha, and Y. Chen, "Assessment of transverse impact damage in GF/EP laminates of conductive nanoparticles using electrical resistivity tomography," Composites Part A: Applied Science and Manufacturing, vol. 43, no. 9, pp. 1587-1598, 2012.

[35] ASTM D2344, "Standard test method for short-beam strength of polymer matrix composite materials and their laminates," in Annual Book of American Society for Testing Materials, vol. 15, pp. 54-60, ASTM, West Conshohocken, Pa, USA, 2007.

[36] ASTM, "Standard test methods for flexural properties of polymer matrix composite materials," ASTM D7264, ASTM International, 2007, http://www.astm.org.

[37] C. P. Wong and R. S. Bollampally, “Thermal conductivity, elastic modulus, and coefficient of thermal expansion of polymer composites filled with ceramic particles for electronic packaging," Journal of Applied Polymer Science, vol. 74, no. 14, pp. 33963403, 1999.

[38] http://exaktusa.com/dispersion-equipment/basic-models/trmbasic-exakt-80/.

[39] P. Banerjee and J. Schmidt, "Electrical conductivity modeling and validation in unidirectional carbon fiber reinforced polymer composites," in Proceedings of the COMSOL Conference, Paper 181149, October 2013.

[40] R. Bacon, "Growth, structure, and properties of graphite whiskers," Journal of Applied Physics, vol. 31, no. 2, pp. 283-290, 1960.

[41] E. Bilotti, R. Zhang, H. Deng, F. Quero, H. R. Fischer, and T. Peijs, "Sepiolite needle-like clay for PA6 nanocomposites: an alternative to layered silicates?" Composites Science and Technology, vol. 69, no. 15-16, pp. 2587-2595, 2009.
[42] H. Deng, T. Skipa, E. Bilotti et al., "Preparation of highperformance conductive polymer fibers through morphological control of networks formed by nanofillers," Advanced Functional Materials, vol. 20, no. 9, pp. 1424-1432, 2010.

[43] H. Zhang, E. Bilotti, W. Tu, C. Y. Lew, and T. Peijs, "Static and dynamic percolation of phenoxy/carbon nanotube nanocomposites," European Polymer Journal, vol. 68, pp. 128-138, 2015.

[44] E. Bilotti, H. Zhang, H. Deng, R. Zhang, Q. Fu, and T. Peijs, "Controlling the dynamic percolation of carbon nanotube based conductive polymer composites by addition of secondary nanofillers: the effect on electrical conductivity and tuneable sensing behaviour," Composites Science and Technology, vol. 74, pp. 85-90, 2013.

[45] C. W. Jennings, "Surface roughness and bond strength of adhesives," The Journal of Adhesion, vol. 4, no. 1, pp. 25-38, 1972.

[46] J. Molina, J. Fernández, J. C. Inés, A. I. Del Río, J. Bonastre, and F. Cases, "Electrochemical characterization of reduced graphene oxide-coated polyester fabrics," Electrochimica Acta, vol. 93, pp. 44-52, 2013.

[47] Y. Li, Y. Zhao, J. Sun, Y. Hao, J. Zhang, and X. Han, "Mechanical and electromagnetic interference shielding properties of carbon fiber/graphene nanosheets/epoxy composite," Polymer Composites, vol. 37, no. 8, pp. 2494-2502, 2016.

[48] P. He, B. Huang, L. Liu, Q. Huang, and T. Chen, "Preparation of multiscale graphene oxide-carbon fabric and its effect on mechanical properties of hierarchical epoxy resin composite," Polymer Composites, vol. 37, no. 5, pp. 1515-1522, 2016.

[49] A. Yu, P. Ramesh, X. Sun, E. Bekyarova, M. E. Itkis, and R. C. Haddon, "Enhanced thermal conductivity in a hybrid graphite nanoplatelet-carbon nanotube filler for epoxy composites," Advanced Materials, vol. 20, no. 24, pp. 4740-4744, 2008.

[50] K. Dong, K. Liu, Q. Zhang, B. Gu, and B. Sun, "Experimental and numerical analyses on the thermal conductive behaviors of carbon fiber/epoxy plain woven composites," International Journal of Heat and Mass Transfer, vol. 102, pp. 501-517, 2016.

[51] J. G. Park, Q. Cheng, J. Lu et al., "High thermal conductivity of carbon nanotube sheet/epoxy composite," in Proceedings of the 18th International Conference on Composites Materials (ICCM '11), Korea, August 2011.

[52] M. Wan, R. R. Yadav, D. Singh, M. Sridhar Panday, and V. Rajendran, "Temperature dependent ultrasonic and thermo-physical properties of polyaniline nanofibers reinforced epoxy composites," Composites Part B: Engineering, vol. 87, pp. 40-46, 2016. 

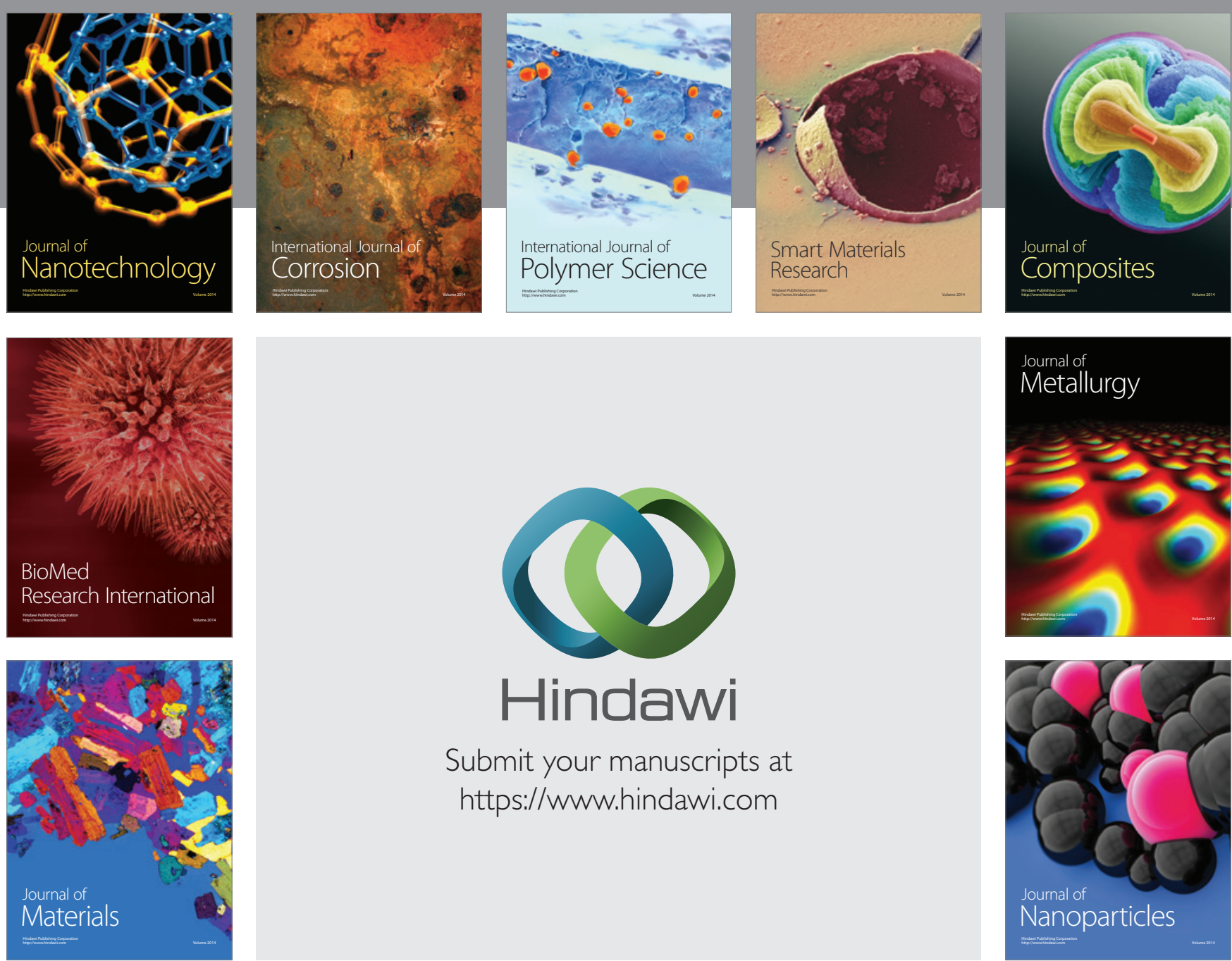

\section{Hindawi}

Submit your manuscripts at

https://www.hindawi.com

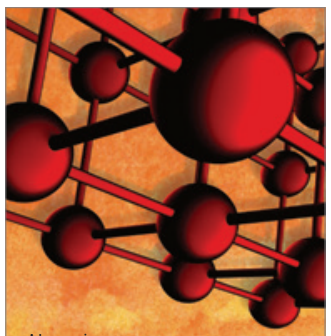

Materials Science and Engineering
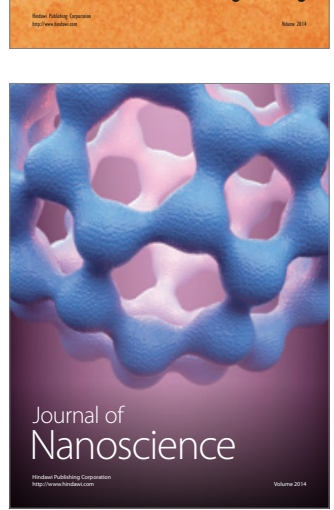
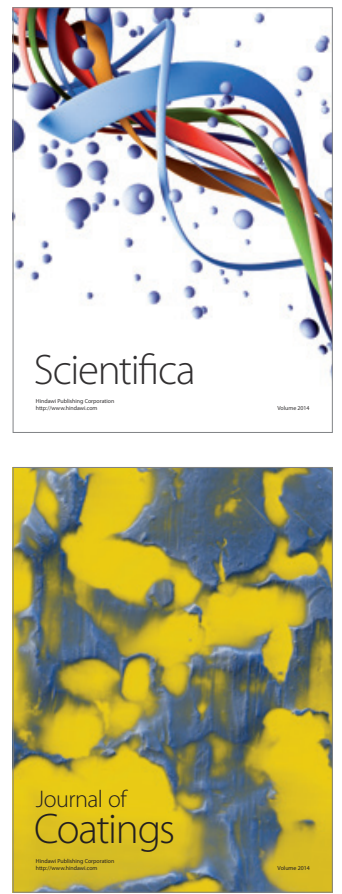
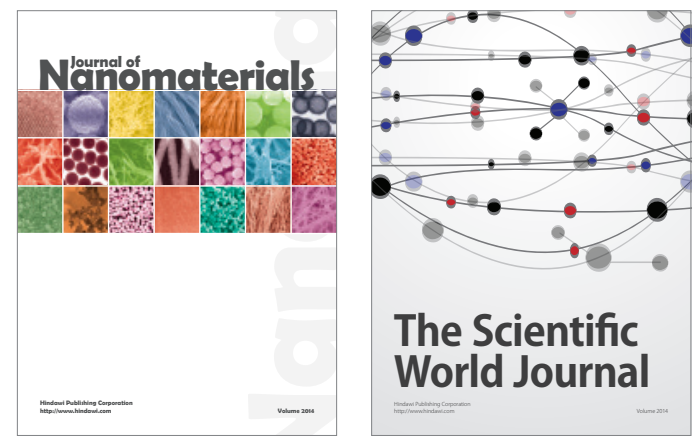

The Scientific World Journal
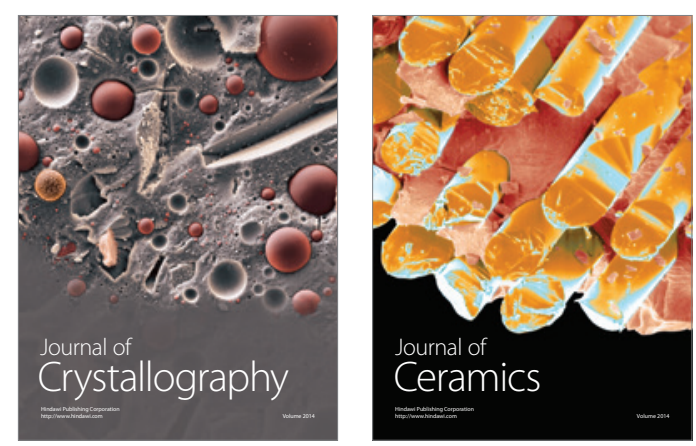
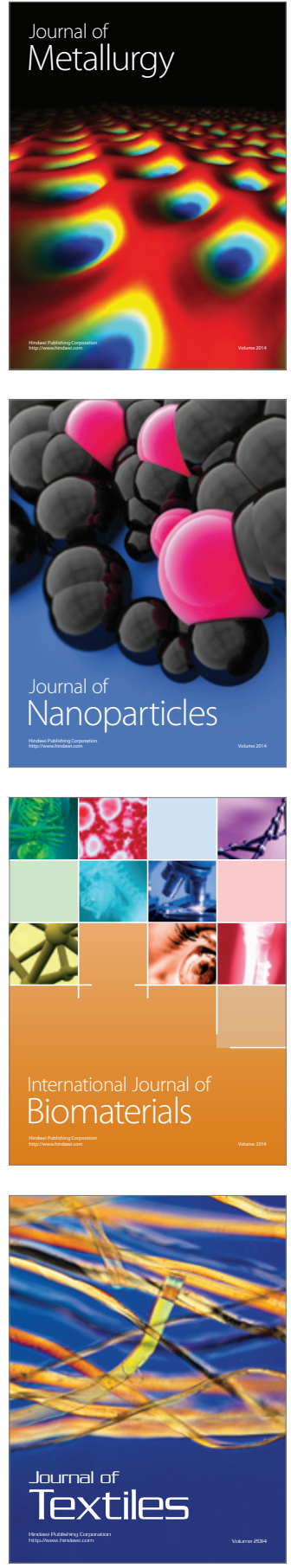